\title{
Induction by young of prolonged dioestrus in virgin rats behaving maternally
}

\author{
M. Jakubowski and J. Terkel \\ Department of Zoology, The George S. Wise Centre for Life Sciences, \\ Tel Aviv University, Tel Aviv, Israel
}

\begin{abstract}
Summary. The present investigation examined, by study of daily vaginal smears, whether the interaction of virgin female rats with young affected the oestrous cycle. Virgins behaving non-maternally or maternally were continuously exposed to young for extended periods. (1) All non-maternal virgins continued to cycle while $87 \%$ of maternal virgins ceased to cycle when exposed to young, and entered a series of prolonged dioestrous phases, each lasting about 14 days. Likewise, all maternal parous non-lactating controls exposed to young entered prolonged dioestrus. (2) The dioestrous phase induced by young in virgins was characterized by the decidual response. (3) Young aged 4-9 days were as effective as 10-15-day-old young for inducing and maintaining the dioestrus. (4) Confinement of young in a wire-mesh basket showed that body contact with young was essential to establish dioestrus. (5) Body contact with young was sufficient to induce dioestrus in maternal virgins with excised nipples. (6) Once established, the dioestrus could be maintained for about 12 days after removal of young as early as Day 4 of dioestrus in virgin and parous nonlactating females, but removal of young on Day 6 from post-partum lactating females resulted in a rapid resumption of cyclicity. (7) Prolonged suckling during a series of dioestrous phases induced lactation in $61 \%$ of maternal virgins, as well as in all parous control females.
\end{abstract}

\section{Introduction}

After the post-partum oestrus, lactating unmated rats and mice experience a prolonged dioestrous phase which ends at the time of weaning (about 3 weeks post partum) with resumption of oestrous cycles (Parkes, 1926; Rothchild, 1960; Bruce, 1961). When suckling is maintained for an extended period, resulting in prolonged lactation, this post-partum dioestrus is followed by cycles with a prolonged dioestrous phase (Parkes, 1926; Crew \& Mirskaia, 1930; Selye \& McKeown, 1934c; Bruce, 1961; Nagasawa \& Yanai, 1976; Tomogane, Ota, Unno \& Yokoyama, 1976). Removal of young during the 3-week post-partum dioestrus leads to a rapid resumption of regular oestrous cycles (Crew \& Mirskaia, 1930; Ota \& Yokoyama, 1965; Moltz, Levin \& Leon, 1969; Zarrow, Johnson, Denenberg \& Bryant, 1973; Maneckjee \& Moudgal, 1975). It is the tactile stimulation by young which induces dioestrus because oestrous cycles resume rapidly after separation from the young by a wire-mesh partition (Zarrow et al., 1973). Nipple stimulation by suckling, which many authors believe to be most important, is not necessarily involved because mothers lacking nipples (Moltz et al., 1969; Zarrow et al., 1973) or nipples and mammae (Moltz, Geller \& Levin, 1967) exhibit a post-partum dioestrus lasting for about 2 weeks.

It was first shown by Selye \& McKeown (1934a, b) and later confirmed by others (Bruce, 1961; Ota \& Yokoyama, 1965; Thoman \& Levine, 1970) that when parous non-lactating cyclic 
females are exposed to young they enter a dioestrous phase lasting about 2 weeks. Selye \& McKeown (1934a) were unable to establish the same phenomenon in virgin rats. Since induction of maternal behaviour in virgin rats by exposure to young requires about 7 days, during which oestrous cyclicity is maintained, it is possible that the virgins in the study of Selye \& McKeown (1934a) continued to cycle regularly because the time with young was too short to induce maternal behaviour. Bruce (1961), however, recorded prolonged dioestrus in 2 virgin rats kept with young for 12 weeks. Therefore, one might expect that virgin rats would enter prolonged dioestrus only after becoming maternal.

The present study examined the long-term effect of exposure to young on vaginal cyclicity in virgin rats, and the stimuli from the young which are involved in the induction and maintenance of dioestrus. Part of this study has been presented in abstract form (Jakubowski \& Terkel, 1977).

\section{Material and General Methods}

\section{Animals}

Sprague-Dawley rats, 4-7 months old and from our own colony (originally obtained from Charles River, Wilmington, Massachusetts, U.S.A.), were maintained in $14 \mathrm{~h}$ light: $10 \mathrm{~h}$ dark schedule (lights on $05: 00 \mathrm{~h}$ ) in a temperature-controlled room $\left(23-24^{\circ} \mathrm{C}\right)$ with food pellets and water supplied ad libitum.

Virgin females were individually housed in plastic cages measuring $34 \times 28 \times 15 \mathrm{~cm}$ with wood shavings and wire lids. Each rat was allowed to habituate to the cage for 2 days, and was then tested for maternal behaviour by presenting 5 foster young, 5-10 days old, at the front of the cage. Some of the females were spontaneously maternal. Maternal behaviour was induced in the others by keeping them with young. The young were provided by a battery of lactating mothers and were replaced daily (Rosenblatt, 1967). Both types of 'maternal' virgin were then transferred to smaller cages measuring $30 \times 20 \times 12 \mathrm{~cm}$, and were given 4 young which were exchanged daily for fresh ones (see 'Results').

Post-partum lactating rats and parous non-lactating females were used as controls and were individually housed in the smaller cages described above. For the post-partum mothers the number of young was adjusted to 4 for each mother within 1 day of birth, and the young were rotated daily among the mothers. To prolong the lactation period, the growing young were replaced with 4-day-old foster young on Day 15 post partum, and thereafter at intervals of about 10 days. To obtain parous non-lactating females, mothers were separated from their young during the lactation period, resulting in resumption of the oestrous cycles. After 3 regular cycles they were again exposed to 4 young, 4-15 days old, which were exchanged daily for fresh ones.

\section{Scoring systems}

Maternal behaviour. Three behaviour patterns were used as criteria for maternal behaviour: (1) retrieving all 5 young, (2) crouching over them, and (3) licking, particularly the anogenital region of the young. These items were scored in a daily 15 -min observation period which began with the introduction of fresh young. The first day of cohabitation was designated Day 0 for measuring the latency to onset of maternal behaviour. 'Non-maternal' virgins were considered to be 'maternal' from the first of the 2 consecutive days during which all 3 components of maternal behaviour occurred.

Vaginal cyclicity. Vaginal smears were taken daily. To simplify the description of the cycle, we adopted the terminology used by Tomogane, Ota \& Yokoyama (1976). Thus, the term 'oestrogenic phase' refers to pro-oestrous and/or oestrous smears. Maternal females that continued to cycle for 25-30 days in spite of being with young were considered to be animals in which prolonged dioestrus could not be induced. The duration of dioestrus was expressed by the 
number of days of leukocytic smears observed between two oestrogenic phases. When the postpartum oestrus was not identified from the vaginal smear of lactating females it was considered to have occurred during the night following parturition, and the day of parturition was designated as Day 0 of dioestrus. In virgin and parous females, the latency to onset of prolonged dioestrus was expressed in terms of the number of oestrogenic phases, excluding the first, that occurred after the first day of maternal behaviour (which could coincide with any day of the oestrous cycle).

Milk secretion was determined by a daily rough visual estimation of the milk content in the stomachs of the foster young at the time they were exchanged for fresh young and was scored as 'much', 'little' or 'none'.

\section{Statistics}

The data, given as mean \pm s.e.m., were analysed using nonparametric statistics (Siegel, 1956), and all tests were two-tailed.

\section{Detailed Methods and Results}

\section{Vaginal cyclicity, milk secretion and decidual response}

Exposure to young induced maternal behaviour in all non-spontaneously maternal virgins $(\mathrm{N}=30)$ within $1-12$ days $(5.9 \pm 0.6$ days). All virgins continued to cycle until the day maternal behaviour first appeared. However, $53(87 \%)$ of the 61 virgins showing maternal behaviour ( 31 were spontaneously maternal) ceased to cycle when exposed to young after a latency of $0.53 \pm$ 0.12 oestrogenic phases and exhibited a prolonged dioestrus lasting $14.3 \pm 0.3$ days. After the oestrogenic phase signalling the end of dioestrus, $94 \%(50 / 53)$ of the virgins entered a second prolonged dioestrus, during which lactation occurred in $4(8 \%)$ of the females. After an interval of 3 oestrous cycles without young, 35 virgins which had experienced 2 dioestrous phases were re-exposed to young. All were immediately maternal and $28(80 \%)$ exhibited a third and fourth prolonged dioestrus. During this period, lactation occurred in $17(61 \%)$ of the virgins. The third prolonged dioestrus was longer $(P<0.02$, Mann-Whitney $U$ test $)$ in virgins that lactated (18.9 \pm 1.5 days) than in those that did not (14.2 \pm 0.5 days).

Parous non-lactating females $(\mathrm{N}=18)$ behaved maternally when exposed to young and immediately exhibited a prolonged dioestrus of $15.9 \pm 0.3$ days. Onset of intense milk secretion occurred in all subjects on Days 14-18 of dioestrus.

The post-partum mothers experiencing prolonged lactation $(N=12)$ exhibited 3 consecutive dioestrous phases throughout the 40-day observation period. The duration of the first dioestrous phase (16.8 \pm 0.2 days), in which lactation was intense, was longer than the second (11.7 \pm 0.2 days), during which milk secretion declined in most of the females $(P<0.005$, Wilcoxon matched pairs signed ranks test). The dioestrous phases in lactating virgin, parous and post-partum rats were similar in duration $(P>0.05$, Kruskal-Wallis one way analysis of variance). Regardless of reproductive background, the duration of dioestrus induced by young was longer in lactating females (about 16-19 days) than in non-lactating rats (about 12-14 days).

In an attempt to produce deciduomata, one uterine horn was traumatized on Day 4 of the dioestrous phase induced by young in 10 spontaneously maternal virgins. By Day 10 the traumatized horn weighed more than the untreated control horn $(968 \pm 181$ and $216 \pm 43 \mathrm{mg}$ respectively, $P<0.005)$. All 10 virgins had corpora lutea averaging $14 \cdot 1 \pm 1 \cdot 1$ in number.

\section{Age of young, induction and duration of dioestrus in virgins}

Maternal virgins were given 4-9-day-old young $(\mathrm{N}=40)$ or 10 -14-day-old young $(\mathrm{N}=21)$. There was no difference in either the proportion of females entering dioestrus ( 86 versus $88 \%$ ) or the duration of dioestrus $(14.4 \pm 0.6$ versus $14.1 \pm 0.4$ days $)$. 


\section{Role of the nipples in young-induced prolonged dioestrus}

Injury of the nipples by suckling had no effect on the induction of prolonged dioestrus in the virgin and parous females. To test whether the presence of nipples was essential for the induction of prolonged dioestrus, the nipples were removed from 10 spontaneously maternal virgins which were continuously exposed to young 3 weeks later. Prolonged dioestrus lasting for 13.2 \pm 0.4 days was immediately entered by 8 of the females

\section{Role of tactile stimuli from young in the establishment of prolonged dioestrus}

This experiment was to examine whether the prolonged dioestrus, once initiated, could be maintained in the absence of young, and if not, whether exteroceptive stimuli from the young could maintain it. On Day 2 of the 2nd dioestrous phase, 12 virgins were separated from young while 28 control virgins remained with young. Beginning on the 2 nd day of the 4 th dioestrous phase, 9 virgins were deprived of tactile stimulation from the young by confining the young in wire-mesh baskets $(10 \times 10 \times 10 \mathrm{~cm})$, while 10 controls remained with freely moving young. By 6 days after the onset of dioestrus, all females kept with young were still in dioestrus, but oestrus had recurred 2-3 days after removal or confinement of young in $11(92 \%)$ and $9(100 \%)$ of the females, respectively.

\section{Influence of removal of young during dioestrus on the maintenance of dioestrus}

This experiment was to test whether the continuous presence of young is required for the maintenance of dioestrus, after it had been established. Experimental groups and results are shown in Table 1. Virgin and parous females maintained dioestrus (lasting 11-16 days) after removal of the young but post-partum lactating mothers did not. As experience with young increased, fewer females maintained dioestrus in the absence of young.

Table 1. Capacity to maintain the young-induced dioestrous phase after removal of the young on Days 4 or 6 of dioestrus in female rats

\begin{tabular}{lcc}
\hline \multicolumn{1}{c}{ Group } & $\begin{array}{c}\text { No. of } \\
\text { rats }\end{array}$ & $\begin{array}{c}\text { No. maintaining } \\
\text { dioestrus (\%)* }\end{array}$ \\
\hline $\begin{array}{l}\text { Naive virgins (1st dioestrus) } \\
\text { Experienced virgins (2nd and }\end{array}$ & 12 & $12(100)^{\dagger}$ \\
$\begin{array}{l}\text { 4th dioestrus) } \\
\text { Parous non-lactating females }\end{array}$ & 27 & $12(63) \dagger$ \\
Post-partum lactating females & 21 & $18(67) \ddagger$ \\
\hline
\end{tabular}

* The four groups were significantly heterogeneous $\left(P<0.001 ; \chi^{2}\right.$ test $)$. test).

$\uparrow$ Significantly different $(P<0.02$, Fisher exact probability

$\ddagger$ Significantly different $\left(P<0.01, \chi^{2}\right.$ test $)$.

\section{Discussion}

The present study shows that when maternal virgin rats are exposed to young, they immediately cease cyclicity and enter a series of prolonged dioestrous phases. This finding supports Bruce's (1961) observation on 2 rats. Marinari \& Moltz (1978) reported that maternal nulliparous rats exposed to foster young of increasing age showed an arrest of ovarian cyclicity, while Koranyi, Phelps \& Sawyer (1977) found that maternal virgin rats housed with young of a constant age 
continued to cycle normally. Marinari \& Moltz (1978) argued that only young of advancing age can evoke an endocrine response that leads to cessation of cyclicity. However, by using young of constant age we have demonstrated that the induction and duration of dioestrus in maternal virgins bears no relation to the age of young, and we have no explanation of why Koranyi et al. (1977) did not observe the same phenomenon.

The prolonged dioestrus in maternal rats appears to be induced by the tactile contact with young which occurs during crouching, rather than by other maternal activities or exteroceptive stimuli from the young. This is supported by the evidence that anaesthesia of the mammary area of post-partum mothers resulted in a rapid resumption of oestrus, despite continuation of normal maternal behaviour (Zarrow et al., 1973). Non-maternal virgins, however, do not experience tactile stimulation from young as they do not crouch over them and they therefore continue to cycle (see Rosenblatt, 1967; Wiesner \& Sheard, 1933). Selye \& McKeown (1934a) were convinced that teat injury would interfere with the induction of dioestrus by young and thus discarded all animals with necrotic teats from their study. However, we found that injury of the nipples by sucking had no effect on the establishment of prolonged dioestrus. In contrast to our observation, Ota \& Yokoyama (1965) reported that parous non-lactating females with injured nipples continued to cycle normally in the presence of young, suggesting that the "... pain in the teats ... causes poor nursing behaviour of the mother ... and leads to a decreased nursing time" (p. 191). This explanation seems inaccurate since mothers suffering from teat injury as a result of pre-partum suckling show normal maternal behaviour (Sachs \& Rosenblatt, 1974). Furthermore, suckling is not required for the induction of dioestrus, since maternal virgins from which the nipples have been removed readily entered a prolonged dioestrus when exposed to young. Therefore, the tactile stimuli from young that are essential for the induction of dioestrus are probably received also through the ventral mammary surface (Zarrow et al., 1973) by the abdominal segmental nerves which innervate the skin overlying the mammary glands as well as the nipples (Findlay, 1966). This concept is supported by the fact that rats with excised nipples and continuously exposed to young had lower serum LH levels (on Days 6 and 12) after parturition than did intact mothers which were deprived of young from the time of parturition (Ford \& Melampy, 1973). In non-lactating women manual stimulation of the breast without manipulating the nipples is able to induce dramatic elevations of plasma prolactin (Kolodny, Jacobs \& Daughaday, 1972).

The present study demonstrates, for the first time, the induction of lactation in virgin rats as a result of prolonged suckling. The duration of dioestrus in lactating females, whether nulliparous or parous, was longer than in non-lactating females. Also the post-partum dioestrus was longer in mothers showing intense lactation than in those having little milk secretion. It appears that mammary activity may prolong dioestrus, thus postponing the onset of the next oestrus.

The presence of corpora lutea and the decidual response during dioestrus induced by young in nulliparous (the present study) and parous (Selye \& McKeown, 1934a, b) rats suggest that these females entered a luteal phase which has characteristics common to the post-partum dioestrus and ordinary pseudopregnancy. In post-partum mothers it is generally agreed, with the exception of one study (van der Schoot, Lankhorst, de Roo \& de Greef, 1978), that the dioestrous phase cannot be maintained after removal of young (Crew \& Mirskaia, 1930; Ota \& Yokoyama, 1965; Moltz et al., 1969; Zarrow et al., 1973; Maneckjee \& Moudgal, 1975; present study). In these females prolactin levels are high when young are present and diminish following removal of young (Amenomori, Chen \& Meites, 1970), allowing the rapid resumption of oestrous cycles (van der Schoot et al., 1978). The dioestrous phase induced by cervical stimulation (i.e. ordinary pseudopregnancy) and the dioestrous phase induced by young in non-lactating females are similar in that, once initiated, both continue in the absence of the triggering stimulus. However, the capacity of the non-lactating females to maintain dioestrus in the absence of young decreases as their previous experience with young increases. It is proposed that in non-lactating females the maintenance of the luteal phase in the absence of young is dependent upon autonomous daily 
prolactin surges, as has been shown in pseudopregnant females (Smith \& Neill, 1976) and in those post-partum mothers which do maintain dioestrus in the absence of young (van der Schoot et al., 1978).

We thank Dr Amelia Terkel for help with the preparation of the manuscript; Dr A. S. Goldblatt, Leah Yogev and Y. Egozi for critical comments; Dr D. Wool for help in the statistical analysis; and Mrs Carmel Meyer for typing the manuscript.

\section{References}

Amenomori, Y., Chen, C.L. \& Meites, J. (1970) Serum prolactin levels in rats during different reproductive states. Endocrinology 70, 506-510.

Bruce, H.M. (1961) Observations on the suckling stimulus and lactation in the rat. J. Reprod. Fert. 2, 17-34.

Crew, F.A.G. \& Mirskaia, L. (1930) The lactation interval in the mouse. Q. Jl exp. Physiol. 20, 105-109.

Findlay, A.C.R. (1966) Sensory discharges from lactating mammary glands. Nature, Lond. 211, 11831184.

Ford, J.J. \& Melampy, R.M. (1973) Gonadotropin levels in lactating rats: effect of ovariectomy. Endocrinology 93, 540-547.

Jakubowski, M. \& Terkel, J. (1977) Suppression of the oestrous cycle and induction of pseudopregnancy by exposure to pups in the virgin albino rat. Israel $J$. Zool. 26, 267-268, Abstr.

Kolodny, R.C., Jacobs, L.S. \& Daughaday, W.H. (1972) Mammary stimulation causes prolactin secretion in non-lactating women. Nature, Lond. 238, 284-286.

Koranyi, L., Phelps, C.P. \& Sawyer, C.H. (1977) Changes in serum prolactin and corticosterone in induced maternal behavior in rats. Physiol. Behav. 18, 287-292.

Maneckjee, R. \& Moudgal, N.R. (1975) The onset of oestrus and ovulation in lactating rats. $J$. Reprod. Fert. 44, 313-315.

Marinari, K.T. \& Moltz, H. (1978) Serum prolactin levels and vaginal cyclicity on concaveated and lactating female rats. Physiol. Behav. 21, 525-528.

Moltz, H., Geller, D. \& Levin, R. (1967) Maternal behavior in the totally mammectomized rat. J. comp. Physiol. Psychol. 64, 225-229.

Moltz, H., Levin, R. \& Leon, M. (1969) Prolactin in the postpartum rat: synthesis and release in the absence of suckling stimulation. Science, N.Y. 163, 10831084.

Nagasawa, H. \& Yanai, R. (1976) Mammary nucleic acids and pituitary prolactin secretion during prolonged lactation in mice. J. Endocr. 70, 389-395.

Ota, K. \& Yokoyama, A. (1965) Resumption of lactation by suckling in lactating rats after removal of litters. J. Endocr. 33, 185-194.

Parkes, A.S. (1926) Observation on the oestrous cycle of the albino mouse. Proc. $R$. Soc. Lond. $B$ 100, 151170.

Rosenblatt, J.S. (1967) Nonhormonal basis of maternal behavior in the rat. Science, N.Y. 156, 1512-1514.
Rothchild, I. (1960) The corpus luteum-pituitary relationship: The association between the cause of luteotrophin secretion and the cause of follicular quiescence during lactation: The basis for a tentative theory of the corpus luteum-pituitary relationship in the rat. Endocrinology 67, 9-41.

Sachs, B.D. \& Rosenblatt, J.S. (1974) Prepartum suckling reduces survival of newborn in the rat. Devl Psychobiol. 7, 399-406.

Selye, H. \& McKeown, T. (1934a) Production of pseudo-pregnancy by mechanical stimulation of the nipple. Proc. Soc. exp. Biol. Med. 31, 683-687.

Selye, H. \& McKeown, T. (1934b) The effect of mechanical stimulation of the nipple on the ovary and the sexual cycle. Surg. Gynaec. Obstet. 59, 886890.

Selye, H. \& McKeown, T. (1934c) Further studies on the influence of suckling. Anat. Rec. 60, 323-332.

Siegel, S. (1956) Nonparametric Statistics for the Behavioral Sciences. McGraw-Hill, New York.

Smith, M.S. \& Neill, J.D. (1976) Termination at midpregnancy of the two daily surges of plasma prolactin initiated by mating in the rat. Endocrinology 98, 696-701.

Thoman, E. \& Levine, S. (1970) Hormonal and behavioral changes in the rat mother as a function of early experience treatments of the offspring. Physiol. Behav. 5, 1417-1421.

Tomogane, H., Ota, K., Unno, H. \& Yokoyama, A. (1976) Changes in body weight, milk production, food and water consumption and vaginal smears in rats during prolonged lactation. Endocr. Japan. 23, 129-136.

Tomogane, H., Ota, K. \& Yokoyama, A. (1976) Duration of diestrous period and secretion of progestins during prolonged lactation in the rat. Endocr. Japan. 23, 137-141.

van der Schoot, P., Lankhorst, R.R., de Roo, J.A. \& de Greef, W.J. (1978) Suckling stimulus, lactation, and suppression of ovulation in the rat. Endocrinology 103, 949-956.

Wiesner, B.P. \& Sheard, N.M. (1933) Maternal Behaviour in the Rat. Oliver \& Boyd, London.

Zarrow, M.X., Johnson, N.P., Denenberg, V.H. \& Bryant, L.P. (1973) Maintenance of lactational diestrum in the post-partum rat through tactile stimulation in the absence of suckling. Neuroendocrinology 11, 150-155. 